\title{
Description of patients consulting the voice clinic regarding gender, age, occupational status, and diagnosis
}

\author{
Angélique Remacle, SLP, PhD ${ }^{1,2}$, Cloé Petitfils, $\mathrm{SLP}^{1}$, Camille Finck, $\mathrm{MD}, \mathrm{PhD}^{2,3,4}$, \& Dominique \\ Morsomme, SLP, PhD $^{1,2}$

\footnotetext{
${ }^{1}$ Faculty of Psychology, Speech and Language Therapy, and Education, University of Liège, Liège, Belgium

${ }^{2}$ Department of Otorhinolaryngology, Liège University Hospital, Liège, Belgium

${ }^{3}$ Faculty of Medicine, University of Liège, Liège, Belgium

${ }^{4}$ Faculty of Psychology and Science of Language, University of Mons, Mons, Belgium
}

Corresponding author: Angélique Remacle, Université de Liège, Faculté de Psychologie,Logopédie et Sciences de l'Education, Unité Logopédie de la Voix, Rue de l'Aunaie, 30 (B38), 4000 Liège, Belgique. Tel: +32 (0)479 6559 84. E-mail: Angelique.Remacle@ulg.ac.be

Institution where the work was done: Department of Otorhinolaryngology, Liège University Hospital, Liège, Belgium.

Paper accepted for publication in European Archives of Oto-Rhino-Laryngology and Head \& Neck Remacle, A., Petitfils, C., Finck, C., \& Morsomme, D. (2016) 


\begin{abstract}
Purpose. To describe the gender, age, occupational status and diagnosis of dysphonic patients.

Method. We retrospectively analyzed the medical records of 1079 patients examined at the Voice clinic of the University hospital of Liège in French-speaking Belgium.

Results. Overall, seven out of 10 patients who attended the voice clinic for dysphonia were females. The patients' ages ranged from 4 to 93 (mean=43.5). Females predominantly consulted at the age of 54 and males at the age of 9. Regarding the occupational status, workers represented more than half of our patients (53\%), while $11.2 \%$ were unemployed, $15.4 \%$ were students, and $19.9 \%$ were retired. Regarding the diagnoses of the 1079 patients, nodules were the most common pathologies $(n=182,16.9 \%$ of the patients), prevailing in females $(n=142,18.8 \%$ of the females $)$, encountered in $16.8 \%$ of the workers and $42.8 \%$ of the students consulting the voice clinic. Following nodules, laryngeal mobility disorders were diagnosed in $16.4 \%$ of the patients $(n=177)$, mainly females $(n=115)$, and was the most frequent diagnosis in retirees $(n=75,34.9 \%)$. Conclusions. The majority of the patients consulting the voice clinic for dysphonia were adult females, in their workforce, diagnosed with vocal nodules. The identification of the patients' characteristics and diagnoses is important to develop treatments and prevention of dysphonia, estimate their costs, and allow comparisons across referral centers.
\end{abstract}

Key words: voice disorders, dysphonia, voice pathology, laryngeal pathology, prevalence, epidemiology 


\section{Introduction}

To date, numerous epidemiological studies have contributed to the inventory and description of voice disorders in general and specific populations. The rationale for such research on voice disorders is to identify populations at risk, to determine the causes and consequences of voice disorders, and to target important cues for diagnosis, treatment and prevention of voice disorders.

Several methods have been used for estimating the prevalence of voice problems, including estimations at the household level, based on questionnaires or telephone surveys [1], and at the healthcare provider service level [2-10]. At the healthcare provider service level, various studies have attempted to identify the gender, age, diagnosis, occupational status and/or profession of patients who seek help for a voice disorder [2-10].

In Poland, Kosztyla-Hojna and collaborators retrospectively analyzed the factors associated with a predis position to occupationaldys phonia in 374 patients separated into two categories: professional voice users and those with other occupations [4]. Sulkowski \& Kowalska analyzed the diagnosis made in 1261 dysphonic patients whose occupations entailed a considerable voice load [5].

In Brazil, Fortes and colleagues surveyed 163 professional voice users seen at a voice clinic in a tertiary health center, and characterized those professionals visiting the clinic more frequently, as well as the incidence of voice disorders in these people [6]. In 2016, the age, gender, profession and diagnoses of 2019 patients who attended the voice disease ambulatories of a Brazilian university hospital were as sessed, disting uishing among 3 occupational statuses: retirees, students, and employed [8].

In Dutch-speaking Belgium, Van Houtte and colleagues described the prevalence of laryngeal pathology in 882 patients diagnosed with dysphonia at a University hospital, differentiating three main groups in the workforce population: professional voice users, non-professionalvoice users, and unemployed or disabled people [2]. De Bodt et al characterized 4447 dysphonic patients referred for voice as sessment and/or voice therapy in terms of gender, age, and diagnoses [10]. No information was reported on patients' occupational status and profession, but valuable information on their voice troubles was presented including subjective (voice handicap index and degree of hoarseness) and objective (dysphonia severity index) parameters.

In the U.S., Herrington-Hall et al. investigated the incidence of laryngeal pathologies in 1262 dysphonic patients seeking treatment by otolaryngologists in Ohio from 1981 to 1983, breaking patients into the following categories: workers, retired, homemaker, unemployed, student and young children [7]. Fifteen years later, Coyle, Weinrich and Stemple repeated the study with 1158 dysphonic patients treated at the same otolaryngology practices in the same geographic region [9] and compared their findings to those of Herrington-Hall et al. [7].

Paper accepted for publication in European Archives of Oto-Rhino-Laryngology and Head \& Neck Remacle, A., Petitfils, C., Finck, C., \& Morsomme, D. (2016) 
From an American insurance claims database, Cohen et al. made a retrospective analys is of 536943 patients diagnosed with dysphonia by primary care physicians and otolaryngologists, taking into account the age and gender [3]. They presented a breakdown of patients according to employment status, but did not address the relationships between employment status and diagnosis, gender, and age.

From a cross-sectional national health interview survey conducted in the U.S., Bhattacharyya estimated an annual prevalence of voice problems among adults of $7.6 \%$ [11]. Among them, $10 \%$ saw a healthcare professional for their voice problem. The study provides data regarding visits to healthcare professionals, including patients' gender, diagnoses, severity of the voice problem, treatment given, and relationship between voice problem and lost workdays.

An overview shows that patient characteristics included and categories of occupationalstatus varied across studies. Some studies addressed exclusively the workforce population [4,6], while others also included retirees and occupationally inactive people [5,11]. Several papers reported an exhaustive description of all patients who consulted for dysphonia [7,9,2,10,8]. However, differences in diagnostic categories and/or occupational status categories make comparisons difficult.

Overall, a higher prevalence of dysphonia is seen in women [2-11] as well as in the working, active, adult population $[2,3,8,10]$. Among workers, occupational voice users are particularly at risk $[2,4,5]$. The most frequently reported diagnoses were functional voice disorders, vocal fold nodules, and laryngitis [2-5,10,11]. The diagnosis according to age shows that vocal fold nodules were the most common pathology in children, functional voice disorders predominate from early adulthood until 65 , while presbyphonia, vocalfold paralysis and functional voice disorders predominate in the elderly $[2,8,10]$.

Based on a retrospective inventory at the healthcare provider service level, the purposes of this study were to describe the population consulting the voice clinic for dysphonia in the French-speaking area of Belgium, and to investigate the distribution of pathologies according to gender, age, and occupational status. Occupational status refers to the patient's occupation at the time of the consultation, including four categories: 1) student, 2) worker, 3) retiree, and 4) unemployed/unable to work. 


\section{Method}

\section{Subjects}

This study was approved by the Ethics Committee of the Faculty of Psychology, Speech and Language Therapy, and Education at the University of Liège, and was performed in accordance with the ethical standards described in the 1964 Declaration of Helsinki and its later amendments. We systematically reviewed the files of patients who had sought consultation fordysphonia at the ambulatory voice clinics of the Otorhinolaryngology Department of Liège University Hospital (French part of Belgium) between January 1, 2009, and December 31, 2013. Made up of laryngologists and speech therapists specializing in voice, the voice clinic practices the evaluation, diagnosis and rehabilitation of voice disorders. Since 2009, medical information of each patient consulting the voice clinic for dysphonia has been registered in a computerized database, with the aim to make an inventory of the characteristics of patients seeking help for a voice problem, and to gatherimportant cues for the treatment and prevention of voice disorders. As a part of a larger research project analyzing the database, this paper focuses on the gender, age, occupational status and diagnosis of patients who had consulted the voice clinic for dysphonia.

Patients were included if they were having their first consultation at the voice clinic for dysphonia. Each patient was included only once in the study. The exclusion criteria were a request for vocal feminization, the presence of a malignant laryngeal lesion or leukoplakia. We excluded malignant laryngeal lesions and leukoplakia because these pathologies are mainly treated in the Head and Neck Surgery Department, another sector of the University Hospital. The final sample comprised 1079 patients examined by both the senior laryngologist of the voice clinic with 25 years of experience in vocal pathologies and laryngeal microsurgery (C.F.) and a trained speech therapist (D.M. or A.R.). For each patient, we analyzed the following data: gender, age, occupational status, and diagnosis made during the first consultation. One out of four occupationalstatuses was attributed to each subject, taking into account his/her main occupation. Among the 1079 patients, there were 166 students (aged 4 to 45), 577 workers (aged 17 to 69), 215 retirees (aged 51 to 93), and 121 unemployed (aged 22 to 60).

\section{Examination methods}

In order to take into account the multidimensional aspect of voice, we followed the protocol elaborated by the Committee on Phoniatrics of the European Laryngological Society, based on five different approaches for assessment of pathological voice conditions [12]. Each patient underwent the following evaluations on the same day: subjective self-evaluations using the Voice Handicap Index [13], perceptual evaluations using the GRBAS 
scale [14] completed by both the laryngologist and the speech therapist; acoustic and aerodynamic measurements realized by the speech therapist, and laryngeal examination performed by the laryngologist. Additionally, each patient filled in the reflux symptom index to detect and score symptoms of laryngopharyngeal reflux [15].

In $85 \%$ of the cases, the laryngeal examination was performed by means of a rigid $90^{\circ}$ endoscope connected to an EndoSTROB (XION GmbH, Berlin, Germany) videolaryngostroboscope. The videos were archived in the DiVAS HD (XION GmbH, Berlin, Germany) Digital Documentation System. Five parameters were evaluated according to the European Laryngological Society guidelines: glottal closure, regularity, mucosal wave, and symmetry of both vocal folds. When a videolaryngostroscopic examination could not be done, a nasofibroscopic examination was conducted in $15 \%$ of the cases using the Olympus Rhino-Laryngo Videoscope ENF-VQ, the Olympus Visera OTV-S7 digital proces sor, and the Olympus Stroboscopic Light source CLL-S1 (Olympus, Antwerpen, Belgium). In a limited number of cases (6\%), a high-speed camera (Color High-Speed Video system, Model 9710 from Kay Pentax, Montvale, NJ) was used in addition to the videolaryngostroboscopy to more clearly visualize mucosal wave mechanics, specifically for patients presenting irregular phonatory cycles and limited phonatory durations. For example, high-speed video provided a more detailed evaluation of mucosal wave in case of sulcus suspicion. The main role of high-speed images was to enhance operative or treatment planning. Research showed that high-speed imaging does not improve the diagnosis accuracy above strobos copy alone [16].

Nodules appear as small, bilateral, mostly symmetric mass lesions (thickenings) of the inferior lip of the vocal folds and result in an hourglass closure glottal configuration [17]. Their localization at the mid portion of the vibrating edge of both vocal folds is due to maximum collisional impacts at that level [18]. These lesions are associated with increased rigidity of the vocal fold mucosal cover and decreased vibration as seen using videolaryngostroboscopy. Voice misuse, overuse and phonatory trauma play an important role in the multifactorial etiology of vocal folds nodules [19]. Contributory factors like lifestyle behavior, personality traits, reflux, and allergy were also identified [19]. The multifactorial etiology of polyp presence is similar [19]. Favoured by aspirin intake [20], polyps may result from sudden mechanical stress like in shouting, coughing, and Valsalva maneuvers [21,22,19]. Polyps are usually unilateral lesions following a vocal fold hemorrhage, deep enough in the superficial layer of the lamina propria to create a blood pooling and further organization into a polyp [23]. As it follows a forceful or prolonged vibration, we consideredema of one or both folds as the step before nodule formation. Resembling small fusiform deformations of the free edge with preserved pliability of the vocal fold cover, edema is a vascularcongestion followed by healing and remodeling of the superficial 
lamina propria [24]. Reinke's edemas are the consequence of heavy smoking: uni or bilateral intense swelling of the Reinke's space leads to polypoid degeneration. Having a form similar to a water drop, pseudocysts are unilateral deforming lesions made of a very superficial accumulation of fluid. Two types of cysts were observed: epidermoid (and in this case, uni or bilateral) and unilateral mucus cysts. Epidermoid cysts are primarily the result of vocal abuse. Mucus cysts can appear spontaneously, created by retention of mucus in a subglottic gland [24]. In the present study, both epidermoid and mucus retention cysts were grouped as cysts. Regarding the definition of Selleck et al [25], we mainly diagnosed type II and III of sulcus vocalis. The type II (sulcus vergeture) is defined as a groove in the vocal fold from atrophy of the superficial layer of the lamina propria. Type III corresponds to an absence of the superficial lamina propria with epithelium adherent to the vocal ligament, with potential involvement of the vocalis muscle. Type III may have the appearance of an open cyst with thickened epithelium [25]. Vocal fold atrophy is characterized by a decreased thicknes s of the vocal fold, which can be achieved by both reduced thickness of the lamina propria and reduced muscle mass of the thyroarythenoid muscle. Both acute and chronic laryngitis were grouped as laryngitis. Laryngopharyngeal reflux (LPR) is the retrograde movement of gastric contents into the larynx, pharynx, and upper aerodigestive tract [26]. The diagnosis of pathologies subsequent to LPR is based on both laryngeal findings and symptoms. The following laryngeal findings are rated by the laryngologist, based on the reflux finding score [26]: subglottic edema, ventricular obliteration, erythema/hyperemia, vocal fold edema, diffuse laryngeal edema, posterior commissure hypertrophy, granuloma/granulation tissue, and excessive endolaryngeal mucus. Functional voice dis order refers to dysphonia in absence of structural or neurological pathology. The distinction between functional voice disorders and normal examination results from voice analyses made by the speech therapist and observation of the patient's vocal behavior. Observed in patients around 60 years -old or greater, presbyphonia refers to the physiological process of aging voice that includes morphological changes in the coverage mucosa, muscle, and cartilage [27]. The clinical characteristics of presbyphonia includes dysfunctionaldisorders as sociated with some degree of vocal fold atrophy. Laryngeal mobility disorders include vocal fold paresis or paralysis, and superior laryngeal nerve injury. The diagnosis is based on nasofibroscopic and videolaryngostroboscopic examinations while the patient performs classical maneuvers (respiration, phonation, sniffing). Laryngeal electromyography is performed only if a differential diagnosis must be made between cricoarytenoid ankylosis and a neurogenic lesion. The clinical signs of superior laryngeal nerve injury are as follow: normal mobility in ab- and adduction, deficit in longitudinal tension, falsetto impossible, restriction of pitch range, and decreased vocal projection. The diagnosis of superior laryngeal nerve injury was most often 
confirmed by laryngeal electromyography. Finally, the least common diagnoses identified in this study were grouped in the "other" category, including psychogenic dysphonia, spasmodic dysphonia, puberphonia in males (failure to change from the high-pitched voice of the pre-adolescence to the lower pitched voice of adulthood), laryngeal papillomatosis, hematoma, post phonosurgery scars, and angiomas.

The diagnoses reported in the present study resulted from a cooperation between the laryngologist, the speech therapist, and the patient, based on the five approaches described above [12]. All factors impacting voice were considered, such as allergy, asthma, smoking habits, gastroesophageal reflux, and influence of medication. As mentioned by Van Houtte et al [2], a classification reporting the major problem "may seem somewhat artificial or limited, because voice literature has extensively confirmed that dysphonia patients are multifactorial in their diagnoses." As in previous studies on patients consulting the voice clinic [2-4,6,8-10], the main diagnosis for each patient was taken into account for the sake of clarity.

\section{Statistics}

For the analysis of the relationship between diagnoses and occupational categories, the chi-square test assessed the null hypothes is that the diagnosis (15 modalities) is independent of the patient's occupational status (4 modalities), using a 5\% level of significance. We then calculated residuals to identify the cells (specific diagnoses and occupational status) making the greatest contribution to the chi-square test result. The larger the residual, the greater the contribution of the cell to the magnitude of the chi-square value. Following a Bonferroni correction, the critical value of 3.2647 was set, meaning that residuals higher than this critical value contribute to the chi-square significance. All calcu lations were conducted using the statistical software Statistica/Win (version 10; StatSoft Inc., Tulsa, OK).

\section{Results}

\section{Gender and age}

Of the 1079 patients who consulted the voice clinic (ages 4 to 93), 754 (69.9\%) were female and 325 (30.1\%) were males. The mean age was identical for both genders (43.5 years), with a median age of 43 for females and 44 for males. The mode shows that females were most likely to consult the voice clinic at the age of 54 and males at the age of 9. Table 1 presents the patients' age according to gender. Figure 1 represents the distribution of patients according to age. 
Table 1. Age according to gender.

\begin{tabular}{lccccc}
\hline & $\mathrm{N}(\%)$ & Mean age (SD) & Min age - Max age & Median age & Mode age \\
\hline Female & $754(69.9 \%)$ & $43.5(17.2)$ & $7-86$ & 43 & 54 \\
Male & $325(30.1 \%)$ & $43.5(21.5)$ & $4-93$ & 44 & 9 \\
Total & $1,079(100 \%)$ & $43.5(18.6)$ & $4-93$ & 43 & 54 \\
\hline
\end{tabular}

Figure 1. Dis tribution of patients according to age.

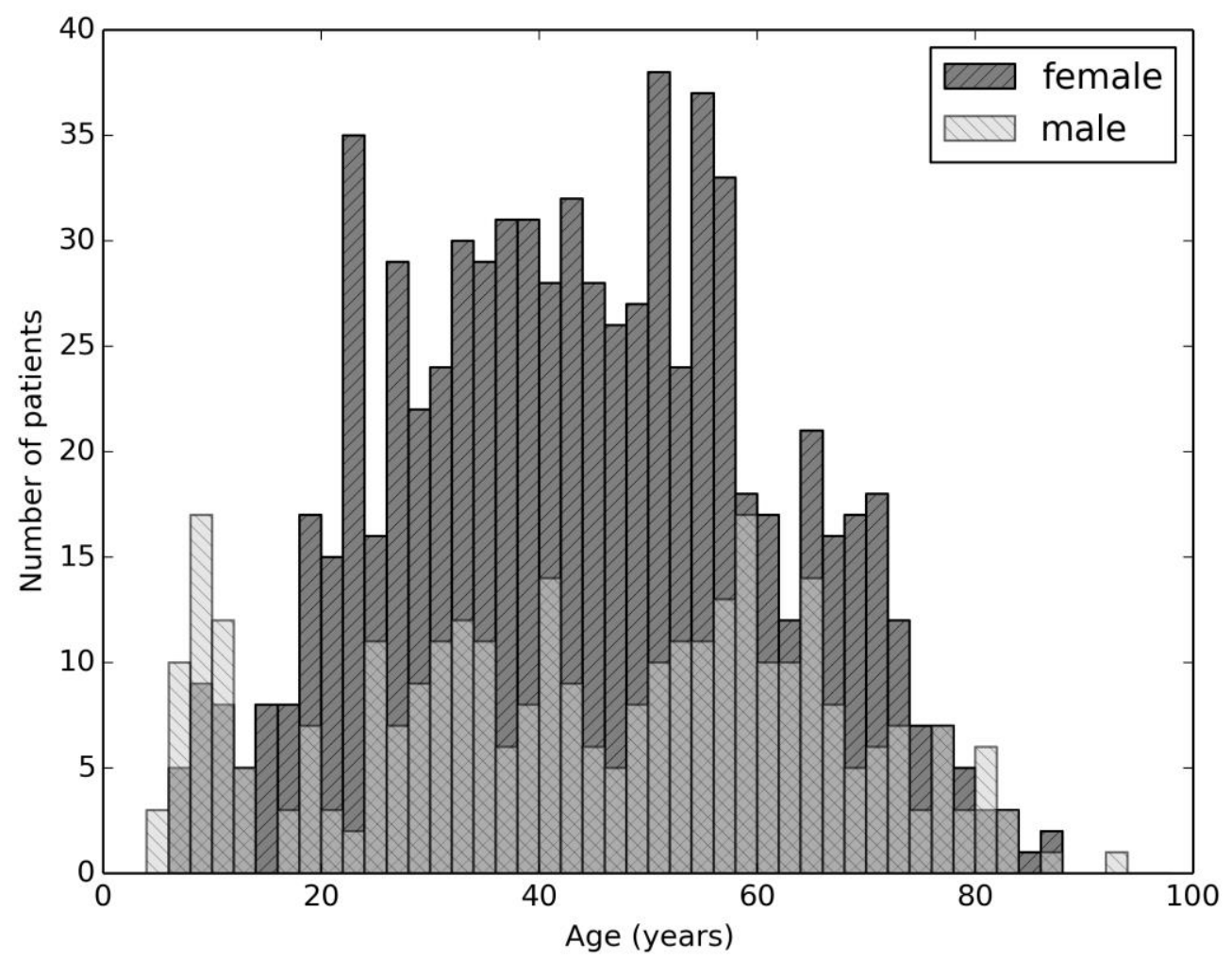

\section{Occupational status}

Among the dysphonic patients examined, 53.5\% were workers (mean age 41.6), 19.9\% were retirees (mean age 69), 15.4\% were students (mean age 15.7), and $11.2 \%$ were unemployed or unable to work (mean age 45.7). The breakdown of students according to level of schooling was: $1.8 \%$ of preschoolpupils (aged under 6), $36.7 \%$ of primary-school pupils (aged 6 to 11 ), $16.9 \%$ of secondary-schoolstudents (aged 12 to 17 ), and $44.6 \%$ of post-secondary students (aged 18 and more). Table 2 describes the patients' age according to occupational status. For each occupationalstatus, dysphonic patients were predominantly females: $61.4 \%$ of females in the students' group, $71.9 \%$ in workers, $63.7 \%$ in retirees and $82.6 \%$ in unemployed patients.

Paper accepted for publication in European Archives of Oto-Rhino-Laryngology and Head \& Neck Remacle, A., Petitfils, C., Finck, C., \& Morsomme, D. (2016) 
Table 2. Age according to occupational status.

\begin{tabular}{lccccc}
\hline & N & Mean age (SD) & Min age - Max age & Median age & Mode age \\
\hline Workers & 577 & $41.6(10.9)$ & $17-69$ & 41 & 41 \\
Retirees & 215 & $69.0(7.2)$ & $51-93$ & 68 & 70 \\
Students & 166 & $15.7(7.1)$ & $4-45$ & 16 & 9 \\
Unemployed & 121 & $45.7(10.4)$ & $22-60$ & 47 & 57 \\
\hline
\end{tabular}

\section{Diagnosis}

Overall, vocal fold nodules represented the most frequent diagnosis (16.9\% of patients), followed by laryngeal mobility problems (16.4\%), normal laryngeal exams (10.4\%), functional dysphonia (10.1\%), edema of one or both vocal folds (8.3\%), polyps (6.6\%), pathologies consecutive to LPR (5.4\%), cysts (4.7\%), Reinke's edema $(4.4 \%)$, sulcus vocalis (3.3\%), vocal fold atrophy (3.1\%), laryngitis (2.8\%), presbyphonia (2.3\%) and pseudocysts $(1.3 \%)$.

The diagnoses according to gender and age are presented in table 3. In females, nodules predominated $(\mathrm{n}=142,18.8 \%$ of females $)$, followed by laryngeal mobility disorders $(\mathrm{n}=115,15.3 \%)$, functional disorders $(\mathrm{n}=80,10.6 \%)$ and edemas $(\mathrm{n}=80,10.6 \%)$. The most common diagnoses in males were laryngeal mobility disorders ( $\mathrm{n}=62,19.1 \%$ of males $)$ and nodules $(\mathrm{n}=40,12.3 \%)$.

Then, we looked at the distribution of laryngeal diagnoses according to occupational status. In workers, the most frequent diagnoses were nodules (16.8\% of workers), laryngeal mobility problems (12.1\%) and functional voice disorders (11.8\%). Retirees most often had laryngeal mobility problems (34.9\% of retirees), vocal fold atrophy $(12.1 \%)$ and presbyphonia (10.2\%). Students presented primarily with nodules (42.8\% of students) and edemas (13.9\%). In unemployed, laryngeal mobility problems represented the most frequent diagnosis (20.7\% of unemployed), followed by edemas, nodules and normal laryngeal exam ( $9 \%$ respectively). The Chi-square test showed that the diagnosis was dependent of the patient's occupational status $\left(\chi^{2}=391.859\right.$, $\mathrm{df}=42, \mathrm{p}<.0001)$. According to the residual analysis, retirees had significantly more presbyphonia $($ residual $=$ $7.6251>3.2647)$, vocal fold atrophy (residual $=7.5750>3.2647)$ and laryngeal mobility problems $($ residual $=$ $6.6902>3.2647)$ than patients pertaining to otheroccupational categories. In addition, the residual analys is showed that students presented significantly more nodules than other occupational categories (residual $=8.1262$ $>$ 3.2647). Finally, table 4 presents the distribution of diagnosis according to occupational status and gender. 
Table 3. Distribution of diagnosis according to gender and age

\begin{tabular}{|c|c|c|c|c|c|c|c|c|c|c|}
\hline & \multicolumn{2}{|c|}{$\mathrm{N}$} & \multicolumn{2}{|c|}{ Mean age (SD) } & \multicolumn{2}{|c|}{ Min age - Max age } & \multicolumn{2}{|c|}{ Median age } & \multicolumn{2}{|c|}{ Mode age } \\
\hline & $\mathrm{F}$ & $\mathrm{M}$ & $\mathrm{F}$ & $\mathrm{M}$ & $\mathrm{F}$ & $\mathrm{M}$ & $\mathrm{F}$ & $\mathrm{M}$ & $F$ & $\bar{M}$ \\
\hline Nodules & 142 & 40 & $30.6(10.8)$ & $16.8(12.1)$ & $7-66$ & $5-54$ & 30.5 & 9 & 23 & 9 \\
\hline Laryngeal mobility disorders & 115 & 62 & $54.3(12)$ & $57.5(12.5)$ & $14-86$ & $11-83$ & 54 & 60 & 54 & 59 \\
\hline Normal on exam & 74 & 38 & $38.6(12.8)$ & $35.4(12.8)$ & $8-86$ & $4-81$ & 38 & 34 & 38 & 26 \\
\hline Functional disorders & 80 & 29 & $46.2(13.9)$ & 48 (11.6) & $15-80$ & $19-75$ & 47 & 51 & 64 & 57 \\
\hline Edema & 80 & 10 & $38.5(13.5)$ & $13.3(5.6)$ & $7-72$ & $6-31$ & 39.5 & 10 & 25 & 10 \\
\hline Polyps & 32 & 39 & $43.8(12.8)$ & $45.2(11.8)$ & $19-79$ & $9-77$ & 40.5 & 45 & 56 & 48 \\
\hline Pathologies consecutive to LPR & 28 & 30 & $44.6(9.4)$ & $43.9(14.8)$ & $23-66$ & $17-81$ & 43.5 & 40.5 & 41 & 32 \\
\hline Cysts & 43 & 8 & $41.5(12.6)$ & $43.3(18)$ & $7-70$ & $12-69$ & 41 & 45 & 43 & / \\
\hline Reinke's edema & 45 & 3 & $51.7(8)$ & $52(6)$ & $26-72$ & $43-59$ & 52 & 54 & 54 & I \\
\hline Sulcus vocalis & 24 & 12 & $44.3(12.8)$ & $42.8(14)$ & $18-72$ & $13-77$ & 41.5 & 40.5 & 34 & 40 \\
\hline Vocal fold atrophy & 17 & 16 & $63(10.1)$ & $67.7(10.5)$ & $38-80$ & $18-93$ & 68 & 68.5 & 68 & 73 \\
\hline Laryngitis & 21 & 9 & $44(9.8)$ & $46(9.8)$ & $15-57$ & $29-62$ & 46 & 48 & 57 & I \\
\hline Presbyphonia & 14 & 11 & $73.6(4.7)$ & $70.2(8.8)$ & $61-82$ & $59-87$ & 74 & 66.5 & 79 & 64 \\
\hline Pseudocysts & 13 & 1 & $34.4(6.8)$ & 8 & $24-50$ & 8 & 32 & I & 24 & I \\
\hline Others & 26 & 17 & $53.6(11.4)$ & $38.5(15.1)$ & $19-77$ & $13-71$ & 54 & 42 & 51 & 13 \\
\hline
\end{tabular}

$\mathrm{F}=$ females; $\mathrm{M}=$ males 
Table 4. Distribution of diagnosis according to occupational status and gender

\begin{tabular}{|c|c|c|c|c|c|c|c|c|c|c|}
\hline & \multicolumn{2}{|c|}{ All patients } & \multicolumn{2}{|c|}{ Workers } & \multicolumn{2}{|c|}{ Retirees } & \multicolumn{2}{|c|}{ Students } & \multicolumn{2}{|c|}{ Unemployed } \\
\hline & $\mathrm{F}$ & $\mathrm{M}$ & $\mathrm{F}$ & $\mathrm{M}$ & $\mathrm{F}$ & $\mathrm{M}$ & F & $\mathrm{M}$ & $\mathrm{F}$ & $\mathrm{M}$ \\
\hline Nodules & $142(18.8 \%)$ & $40(12.3 \%)$ & $87(21 \%)$ & $10(6.2 \%)$ & $2(1.5 \%)$ & $0(0 \%)$ & $41(40.2 \%)$ & $30(46.9 \%)$ & $12(12 \%)$ & $0(0 \%)$ \\
\hline Laryngeal mobility disorders & $115(15.3 \%)$ & $62(19.1 \%)$ & $48(11.6 \%)$ & $22(13.6 \%)$ & $43(31.4 \%)$ & $32(41 \%)$ & $5(4.9 \%)$ & $2(3.1 \%)$ & $19(19 \%)$ & $6(28.6 \%)$ \\
\hline Normal on exam & $74(9.8 \%)$ & $38(11.7 \%)$ & $40(9.6 \%)$ & $26(16 \%)$ & $9(6.6 \%)$ & $2(2.6 \%)$ & $16(15.7 \%)$ & $7(10.9 \%)$ & $9(9 \%)$ & $3(14.3 \%)$ \\
\hline Functional disorders & $80(10.6 \%)$ & $29(8.9 \%)$ & $47(11.3 \%)$ & $21(13 \%)$ & $15(10.9 \%)$ & $6(7.7 \%)$ & $9(8.8 \%)$ & $0(0 \%)$ & $9(9 \%)$ & $2(9.5 \%)$ \\
\hline Edema & $80(10.6 \%)$ & $10(3.1 \%)$ & $49(11.8 \%)$ & $1(0.6 \%)$ & $5(3.6 \%)$ & $0(0 \%)$ & $14(13.7 \%)$ & $9(14.1 \%)$ & $12(12 \%)$ & $0(0 \%)$ \\
\hline Polyps & $32(4.2 \%)$ & $39(12 \%)$ & $25(6 \%)$ & $29(17.9 \%)$ & $3(2.2 \%)$ & $4(5.1 \%)$ & $2(2 \%)$ & $2(3.1 \%)$ & $2(2 \%)$ & $4(19 \%)$ \\
\hline Pathologies consecutive to LPR & $28(3.7 \%)$ & $30(9.2 \%)$ & $17(4.1 \%)$ & $19(11.7 \%)$ & $4(2.9 \%)$ & $4(5.1 \%)$ & $2(2 \%)$ & $3(4.7 \%)$ & $5(5 \%)$ & $4(19 \%)$ \\
\hline Cysts & $43(5.7 \%)$ & $8(2.5 \%)$ & $20(4.8 \%)$ & $4(2.5 \%)$ & $8(5.8 \%)$ & $2(2.6 \%)$ & $5(4.9 \%)$ & $2(3.1 \%)$ & $10(10 \%)$ & $0(0 \%)$ \\
\hline Reinke's edema & $45(6 \%)$ & $3(0.9 \%)$ & $27(6.5 \%)$ & $2(1.2 \%)$ & $10(7.3 \%)$ & $1(1.3 \%)$ & $0(0 \%)$ & $0(0 \%)$ & $8(8 \%)$ & $0(0 \%)$ \\
\hline Sulcus vocalis & $24(3.2 \%)$ & $12(3.7 \%)$ & $14(3.4 \%)$ & $8(4.9 \%)$ & $5(3.6 \%)$ & $2(2.6 \%)$ & $2(2 \%)$ & $2(3.1 \%)$ & $3(3 \%)$ & $0(0 \%)$ \\
\hline Vocal fold atrophy & $17(2.3 \%)$ & $16(4.9 \%)$ & $5(1.2 \%)$ & $0(0 \%)$ & $12(8.8 \%)$ & $14(17.9 \%)$ & $0(0 \%)$ & $1(1.6 \%)$ & $0(0 \%)$ & $1(4.8 \%)$ \\
\hline Laryngitis & $21(2.8 \%)$ & $9(2.8 \%)$ & $12(2.9 \%)$ & $8(4.9 \%)$ & $0(0 \%)$ & $1(1.3 \%)$ & $3(2.9 \%)$ & $0(0 \%)$ & $6(6 \%)$ & $0(\%)$ \\
\hline Presbyphonia & $14(1.9 \%)$ & $11(3.4 \%)$ & $0(0 \%)$ & $3(1.9 \%)$ & $14(10.2 \%)$ & $8(10.3 \%)$ & $0(0 \%)$ & $0(0 \%)$ & $0(0 \%)$ & $0(0 \%)$ \\
\hline Pseudocysts & $13(1.7 \%)$ & $1(0.3 \%)$ & $11(2.7 \%)$ & $0(0 \%)$ & $0(0 \%)$ & $0(0 \%)$ & $2(2 \%)$ & $1(1.6 \%)$ & $0(0 \%)$ & $0(0 \%)$ \\
\hline Others & $26(3.4 \%)$ & $17(5.2 \%)$ & $13(3.1 \%)$ & $9(5.6 \%)$ & $7(5.1 \%)$ & $2(2.6 \%)$ & $1(1 \%)$ & $5(7.8 \%)$ & $5(5 \%)$ & $1(4.8 \%)$ \\
\hline Total & $754(100 \%)$ & $325(100 \%)$ & $415(100 \%)$ & $162(100 \%)$ & $137(100 \%)$ & $78(100 \%)$ & $102(100 \%)$ & $100(100 \%)$ & $100(100 \%)$ & $21(100 \%)$ \\
\hline
\end{tabular}

$\mathrm{F}=$ number of females $(\%) ; \mathrm{M}=$ number of males $(\%) ; \mathrm{LPR}=$ laryngopharyngeal reflux 


\section{Discussion}

In this retrospective study, we described the data related to gender, age, occupational status and diagnosis of 1079 patients examined at a voice clinic in French-speaking Belgium. Additionally, we investigated the distribution of vocal pathologies according to the patients' gender, age, and occupational status.

\section{Gender and age}

Regarding the distribution by gender, patients consulting the voice clinic for dysphonia were $69.9 \%$ female and 30.1\% male. In the Dutch-speaking area of Belgium, slightly lower proportion of females was observed (61\% and 64\%) [2,10]. American and Brazilian studies reported that females represent $61 \%$ to $63.4 \%$ of the dysphonic treatments-seeking population [3,8,9]. Contrary to our study including only benign pathologies, the lower female prevalence of dysphonia in these studies may be explained by the inclusion of malignant pathologies. Laryngeal cancers were shown to occur significantly more often in males than in females $[9,10]$. In agreement with previous studies [2,28], the overall results suggest that females are about twice as likely to seek care for voice problems compared to males. This disparity between genders may be explained by differences in laryngeal structures, posterior glottis closure, molecular composition of the vocal folds tissues, hormonal factors and a higher fundamental frequency implying a greater load for vocal folds in females [29-31].

Although the mean age of our patients was similar for both genders, the mode shows that females were most likely to consult the voice clinic at the age of 54 and males at the age of 9 . For females, visual analysis of the figure 1 shows peaks between 50 and 60, as well as in the 20-22 years old category.

\section{Occupational status}

More than half of the patients $(53.5 \%)$ who sought help for a voice disorder were in the work force. The mode shows that the largest number of workers visited the clinic at age 41. Patients pertaining to this group may be more prone to seek consultation for their voice because they are active and some of them may need their voice for their job, these people being referred to as professionalvoice users. Of the workforce population, professional voice users accounted for $41 \%$ of the patients seeking consultation for their voice in Dutch-speaking Belgium [2].

Of the non-working patients, 215 were retired (19.9\% of the total sample), 166 were students ( $15.4 \%$ of the total sample), and 121 were unemployed or unable to work (11.2\% of the total sample). The large nu mber of retired persons (one out of five patients) may be due to effects of aging on the three systems involved in voice production: respiratory, vibrator, and resonator. Senility process es affecting laryngeal structures include

Paper accepted for publication in European Archives of Oto-Rhino-Laryngology. Remacle, A., Petitfils, C., Finck, C., \& Morsomme, D. (2016). DOI: 10.1007/s00405-016-4332-7 
morphological changes in its coverage mucosa, as well as muscle, cartilaginous, neurological, and functional alterations [27]. Similarly, a high proportion of retired persons was reported in previous studies [7,9].

When we look at the genderbreakdown according to occupation, it appears that a higher proportion of females consulted the voice clinic regardless of occupationalstatus. However, a lower proportion of females was observed in the students ( $61 \%$ of females) compared to the other occupationalcategories $(64 \%$ of females in retirees, $72 \%$ in workers, and $83 \%$ in unemployed patients). Previous studies on dysphonic patients showed a predominance of males in children, while females predominated in adults [3,8].

\section{Diagnosis}

In the total sample, vocal fold nodules represented the main diagnosis overall (16.9\% of our patients). Earlier studies also reported nodules as the most frequent laryngeal pathology, encountered in $21.6 \%$ [7] to $23 \%$ [10] of the patients. As in previous publications [6,8-10,31], the genderbreakdown showed that vocal fold nodules were more frequent in women $(\mathrm{N}=142,18.8 \%$ of the females) than in men $(\mathrm{N}=40,12.3 \%$ of the males). It was hypothesized that mechanical stress experienced during high-pitched vibration is confined to the edge of the vocal fold, predisposing to the formation of nodules via activation of subepithelial fibroblasts and consequent excessive collagenous fiber deposition [31,32]. However, the difference in mean speaking frequency provides only a partial explanation [17]. Higher prevalence of nodules in females may also be explained by intrinsic differences in laryngeal anatomy and phonatory physiology, including differences in phonatory air pressure, in posterior glottis closure and in the ability of the membranous vocal fold to absorb phonotrauma [31]. According to Butler et al [29], the lower proportion of hyaluronic acid in females' superficial layer of the lamina propria and thus less shock-absorbing capacity as well as decreased capacity for tissue repair may amplify the potential for damage related to high frequency vibrations.

We note a clear predisposition to nodules, edema, and pseudocysts in young females (between 20 and 40 years old $)$. In the female workers, nodules $(\mathrm{N}=87,21 \%)$ and edema $(\mathrm{N}=49,11.8 \%)$ were the most frequent diagnoses. These pathologies may be due to the posterior glottis insufficiency and higher fundamental frequency in young compared to older females [31,33]. Recent studies proposed that physiologic posterior glottis insufficiency functions as a sort of pseudo-paresis that predisposes females to phonotraumatic injury and development of pseudocysts [31,34]. The physiopathology of pseudocyst formation may mimic that of nodules, providing a common explanation for the strong association of these two pathologies with the female gender [31]. Similar to other studies [6,31], Reinke's edema was mainly observed in older females and may be explained by the cumulative effects of cigarette smoke. As the rough and low-pitched voice following Reinke's edema is more

Paper accepted for publication in European Archives of Oto-Rhino-Laryngology.

Remacle, A., Petitfils, C., Finck, C., \& Morsomme, D. (2016). DOI: 10.1007/s00405-016-4332-7 
disturbing in females, it is unclear to what extent the association with female patients is explained by the disproportionate representation of women in the patients consulting the voice clinic [31]. Cysts were also mainly observed in females, as in de Bodt et al (2015) [10].

Laryngeal mobility problems, including vocal fold paresis or paralysis, and superior laryngeal nerve injury, were the second most common diagnos is in the total sample (16.4\% of the patients). Similar percentages were reported in Dutch-speaking Belgium: 14\% vocal fold paralysis [10]. Laryngeal mobility disorders were mainly diagnosed in males and females between 50 and 60 years old. Van Houtte and collaborators reported that vocal fold paralysis was detected in $17 \%$ of the patients older than 65 [2].

In the case of retirees, laryngeal mobility problems were the most frequent diagnoses, found in $31.4 \%$ of the females and $41 \%$ of the males. Following laryngeal mobility problems, vocal fold atrophy was encountered in $8.8 \%$ of the retired females and $17.9 \%$ of the retired males, and presbyphonia in $10.2 \%$ of the retired females and $10.3 \%$ of the retired males. Similarly, Herrington-Hall et al. [7] and Coyle et al. [9] observed that vocal fold paralys is was the most frequent diagnosis among retirees (15.9\% and $18.9 \%$ of retirees, respectively). As in previous studies $[2,7,9,10]$, the prevalence of laryngeal mobility problems increased with age: laryngeal mobility disorders were found in $4.2 \%$ of the students, $12.1 \%$ of the workers, and $34.9 \%$ of the retirees. Etiologies of laryngeal mobility disorders include malignancies, surgery, and idiopathic causes. Prevalence of thyroid disorders increases with age and thyroid cancer mostly occurs after fifty years of age [35, 36]. Cantarella et al showed that the main etiology of unilateral vocal fold paralysis was thyroidectomy in middle aged patients, head and neck surgery in elderly patients, and idiopathic origin in the youngest patients [35]. Based on this study, we hypothesize that the high proportion of laryngeal mobility disorders found in workers and in the unemployed is due to thyroid surgery, while its very high proportion in retirees is likely due to head and neck surgery and malignancy.

In the specific case of workers, the most frequent diagnoses were nodules, laryngeal mobility problems and functional voice disorders. Kosztyla-Hojna et al also found that nodules predominated in workers treated for dysphonia, particularly in professional voice users [4]. For these people, occupation may entail extensive voice use. Phonotrauma associated with both voice overuse and misuse is known to cause vocal fold nodules [19]. Polyps were the most common pathologies detected in male workers $(\mathrm{N}=29,17.9 \%)$ aged around 40 . These lesions may be consecutive to mechanical stress: it was hypothesized that low-pitched stress predisposes to the rupture of blood vessels in the deeper portion of the lamina propria and causes hemorrhage inducing polyps

Paper accepted for publication in European Archives of Oto-Rhino-Laryngology.

Remacle, A., Petitfils, C., Finck, C., \& Morsomme, D. (2016). DOI: 10.1007/s00405-016-4332-7 
Students presented primarily with nodules and edema. Statistical analyses showed significantly more nodules in students than in other patients. According to the gender breakdown, the prevalence of these pathologies is similar in female and male students:nodules were found in $40.2 \%$ of the females and $46.9 \%$ of the males, and edema was encountered in $13.7 \%$ of the females and $14.1 \%$ of the males. In the same way, Coyle et al identified nodules as the most frequent diagnosis in students [9]. Van Houtte and collaborators found that nodules were the most frequently detected pathology (63\%) in treatment-seeking children from 0 to 14 years, with no female or male predisposition [2]. Martins and collaborators showed that nodules predominated in children from 1 to 12, with a higher prevalence in boys [8]. In the present study, the mode shows that nodules were mainly diagnosed at the age of 23 in females and at the age of 9 in males. Based on the relationship between fundamental frequency and increase in collisional trauma, the higher proportion of nodules and edema in students may be explained by their higher fundamental frequency compared to older patients [31].

Two more diagnoses merit deeper discussion. Firstly, the proportion of pathologies consecutive to LPR (5.4\% of the patients) is slightly lower compared to previous studies reporting $8 \%$ to $18 \%$ of gastroesophageal reflux diseases in dysphonic patients [2,9,11]. According to Koufman, reflux may be present in up to $50 \%$ of patients with voice disorders [37]. However, the present study exclusively reports LPR when it is the main diagnosis, and do not list gastroesophageal reflux as an as sociated symptom. Secondly, 3.3\% of patients were reported as having sulcus vocalis in this data set. Taking into account the difficulty of visualizing sulcus vocalis using the videolaryngostroboscopy, we have to consider the possibility of under diagnosis or confusion between sulcus vocalis and cysts [25].

Finally, some methodological limits need to be addressed. This descriptive study of a clinical sample is based on the diagnosis realized by the senior laryngologist, as sisted by a speech therapist. The fact that all laryngeal examinations were performed by the same laryngologist avoids bias related to inter-rater variability. However, incorrect diagnosis still remains possible. The diagnosis was based on 1) anamnesis of the patient and laryngeal examination performed by the laryngologist, 2) functional voice assessment, acoustic and aerodynamic measurements realized by the speech therapist, and 3) the patient's history and complaints. As the diagnosis results from a consensus involving these three persons, a retrospective blinded review of a subset of randomly selected video recordings by the laryngologist who performed the study and any number of other graders would not be representative of the clinical context. Consequently, we couldn't check for the inter- or intra-judge reliability of the diagnosis. It remains unknown how consistently the same diagnosis would be made if the

Paper accepted for publication in European Archives of Oto-Rhino-Laryngology.

Remacle, A., Petitfils, C., Finck, C., \& Morsomme, D. (2016). DOI: 10.1007/s00405-016-4332-7 
patients were re-examined a second time by the same (para-)medical team, or how the diagnoses rendered would agree with those provided by another team using the same criteria. Similarly, other reports on dysphonic patients could not offer inter and intra-examiners reliability checks [2-4,6,8-10]. As with every clinical study, this data set needs careful interpretation and generalization.

\section{Conclusion}

In this retrospective analysis of 1079 patients who visited the voice clinic, the predominance of dysphonia in women was confirmed: seven out of 10 patients were female. Among all patients aged from 4 to 93, females mainly consulted at the age of 54 and males at the age of 9 . The occupationalstatus analysis showed that more than half of the patients were workers, $19.9 \%$ were retired, $15.4 \%$ were students and $11.2 \%$ were unemployed.

Looking at the diagnoses, nodules and laryngeal mobility disorders were the most frequently detected pathologies in patients. The distribution of laryngeal diagnoses according to occupational status showed that nodules were the most frequent diagnosis among workers and students, while retirees most often suffered from laryngeal mobility problems, vocal fold atrophy, and presbyphonia.

The large proportion of female workers consulting the voice clinic (38.5\% of the patients) indicates that prevention programs should primarily address this section of the population, especially when considering previous studies according to which occupational voice users are particularly at risk. Moreover, one in every of five of these female workers had vocal fold nodules. For pathologies due to phonotrauma, prevention and treatment should address both voice overuse and misuse.

A future study will examine the distribution of diagnoses according to profession in the workforce population, in order to target the populations at risk of seeking consultation for voice disorders.

Paper accepted for publication in European Archives of Oto-Rhino-Laryngology.

Remacle, A., Petitfils, C., Finck, C., \& Morsomme, D. (2016). DOI: 10.1007/s00405-016-4332-7 


\section{References}

1. Roy N, Merrill RM, Thibeault S, Parsa RA, Gray SD, Smith EM (2004) Prevalence of voice disorders in teachers and the general population. J Speech Lang Hear R 47 (2):281-293. doi:10.1044/1092-4388(2004/023)

2. Van Houtte E, Van Lierde K, D'Haeseleer E, Claeys S (2010) The prevalence of laryngeal pathology in a treatment-seeking population with dysphonia. Laryngoscope 120 (2):306-312. doi:10.1002/lary.20696

3. Cohen SM, Kim J, Roy N, Asche C, Courey M (2012) Prevalence and causes of dysphonia in a large treatment-seeking population. Laryngoscope 122 (2):343-348. doi:10.1002/lary.22426

4. Kosztyła-Hojna B, Rogowski M, Ruczaj J, Pepiński W, Łobaczuk-Sitnik A (2004) An analysis of occupational dys phonia diagnosed in the north-east of Poland. Int J Occup Med Env 17 (2):273-278

5. Sułkowski WJ, Kowalska S (2005) Occupational voice disorders: An analysis of diagnoses made and certificates issued in 1999-2004. Int J Occup Med Env 18 (4):341-349

6. Fortes FSG, Imamura R, Tsuji DH, Sennes LU (2007) Profile of voice professionals seen in a tertiary health center. Braz J Otorhinolaryngol 73 (1):27

7. Herrington-Hall BL, Lee L, Stemple JC, Niemi KR, McHone MM (1988) Description of laryngeal pathologies by age, sex, and occupation in a treatment-seeking sample. J Speech Hear Disord 53 (1):57-64. doi:10.1044/jshd.5301.57

8. Martins RHG, do Amaral HA, Tavares ELM, Martins MG, Gonçalves TM, Dias NH (in press) Voice disorders: Etiology and diagnosis. J Voice. doi:http://dx.doi.org/10.1016/j.jvoice.2015.09.017

9. Coyle SM, Weinrich BD, Stemple JC (2001) Shifts in relative prevalence of laryngeal pathology in a treatment-seeking population. J Voice 15 (3):424-440. doi:10.1016/S0892-1997(01)00043-1

10. De Bodt M, Van den Steen L, Mertens F, Raes J, Van Bel L, Heylen L, Pattyn J, Gordts F, van de Heyning P (2015) Characteristics of a dysphonic population referred for voice assessment and/or voice therapy. Folia Phoniatr Logo 67 (4):178-186. doi:10.1159/000369339

11. Bhattacharyya N (2014) The prevalence of voice problems among adults in the United States. Laryngoscope 124 (10):2359-2362. doi:10.1002/lary.24740

12. Dejonckere PH, Bradley P, Clemente P, Cornut G, Crevier-Buchman L, Friedrich G, Van De Heyning P, Remacle M, Woisard V (2001) A basic protocol for functional assessment of voice pathology, especially for investigating the efficacy of (phonosurgical) treatments and evaluating new assessment techniques. Guideline

Paper accepted for publication in European Archives of Oto-Rhino-Laryngology.

Remacle, A., Petitfils, C., Finck, C., \& Morsomme, D. (2016). DOI: 10.1007/s00405-016-4332-7 
elaborated by the Committee on Phoniatrics of the European Laryngological Society (ELS). Eur Arch Oto Rhino-L 258 (2):77-82

13. Jacobson BH, Johnson A, Gry walski C, Silberg leit A, Jacobson G, Benninger MS, Newman CW (1997) The voice handicap index (VHI): Development and validation. Am J Speech-Lang Pat 6 (3):66-69

14. Hirano M (1981) Clinical examination of voice. Springer, New York

15. Belafsky PC, Postma GN, Koufman JA (2002) Validity and reliability of the reflux sy mptom index (RSI). J Voice 16 (2):274-277

16. Mendelsohn AH, Remacle M, Courey MS, Gerhard F, Postma GN (2013) The diagnostic role of high-speed vocal fold vibratory imaging. J Voice 27 (5):627-631. doi:10.1016/j.jvoice.2013.04.011

17. Dejonckere PH, Kob M (2009) Pathogenesis of vocal fold nodules: New insights from a modelling approach.

Folia Phoniatr Logo 61 (3):171-179. doi:10.1159/000219952

18. Gunter HE (2004) Modeling mechanical stresses as a factor in the etiology of benign vocal fold lesions. J Biomech 37 (7):1119-1124. doi:10.1016/j.jb io mech.2003.11.007

19. Karkos PD, McCormick M (2009) The etiology of vocal fold nodules in adults. Curr Opin Otolaryngo 17 (6):420-423. doi:10.1097/MOO.0b013e328331a 7f8

20. Anniko M, Bernal-Sprekelsen M, Bonkowsky V, Bradley P, Iurato S (2010) Otorhinolaryngology, Head and Neck Surgery. Springer, Berlin Heidelberg

21. Thibeault SL, Ford CN, Gray SD, Smith ME, Li W, Davis RK (2002) Genotypic and phenotypic expression of vocal fold polyps and Reinke's edema: A preliminary study. Ann Oto Rhinol Laryn 111 (4):302-309

.22. Titze IR (2000) Principles of Voice Production, 2nd edn, vol 104. National Center for Voice and Speech. Iowa City

23. Bastian R (1998) Benign vocal fold mucosal disorders. In: Cummings CWH, L. A.; Krause, C. J.; Richardson, M. A. ; Schuller, D. E. (ed) Otolaryngology Head \& Neck Surgery, 3rd edn. US, Mosby, St. Louis, pp 2096-2129

24. Altman KW (2007) Vocal fold masses. Otolaryng Clin N Am 40 (5):1091-1108

25. Selleck AM, Moore JE, Rutt AL, Hu A, Sataloff RT (2015) Sulcus vocalis (Type III): Prevalence and strobovideolaryngoscopy characteristics. J Voice 29 (4):507-511. doi:10.1016/j.jvo ice.2014.09.015

26. Belafsky PC, Postma GN, Koufman JA (2001) The validity and reliability of the reflux finding score (RFS).

Laryngoscope 111 (8):1313-1317. doi:10.1097/00005537-200108000-00001

27. Martins R, Gonçalves T, Pessin A, Branco A (2014) Aging voice: Presbyphonia. Aging Clin Exp Res 26:1-5. Paper accepted for publication in European Archives of Oto-Rhino-Laryngology.

Remacle, A., Petitfils, C., Finck, C., \& Morsomme, D. (2016). DOI: 10.1007/s00405-016-4332-7 
28. Fritzell B (1996) Voice disorders and occupations. Logop Phoniatr Voco 21 (1):7-12. doi:10.3109/14015439609099197

29. Butler JE, Hammond TH, Gray SD (2001) Gender-related differences of hyaluronic acid distribution in the human vocal fold. Laryngoscope 111 (5):907-911. doi:10.1097/00005537-200105000-00029

30. Hunter EJ, Tanner K, Smith ME (2011) Gender differences affecting vocal health of women in vocally demanding careers. Logop Phoniatr Voco 36 (3):128-136. doi:10.3109/14015439.2011.587447

31. Zhukhovitskaya A, Battaglia D, Khosla SM, Murry T, Sulica L (2015) Gender and age in benign vocal fold lesions. Laryngoscope 125 (1):191-196. doi:10.1002/lary.24911

32. Hirano M, Kurita S, Matsuo K, Nagata K (1980) Laryngeal tissue reaction to stress. In: Lawrence V, ed. 9th Symposium on Care of the Professional Voice. New York, NY: The Voice Foundation; 1980:10-20.

33. Linville SE (1992) Glottal gap configurations in two age groups of wo men. J Speech Hear Res 35 (6):12091215

34. Estes C, Sulica L (2014) Vocal fold pseudocyst: Results of 46 cases undergoing a uniform treatment algorithm. Laryngoscope 124 (5):1180-1186. doi:10.1002/lary.24451

35. Cantarella G, Dejonckere P, Galli A, Ciabatta A, Gaffuri M, Pignataro L, Torretta S (2016) A retrospective evaluation of the etiology of unilateral vocal fold paralysis over the last 25 years. Eur Arch Otorhinolaryngol. doi:10.1007/s00405-016-4225-9

36. Reiners C, Wegscheider K, Schicha H, Theissen P, Vaupel R, Wrbitzky R, Schumm-Draeger P-M (2004) Prevalence of thyroid disorders in the working population of Germany: Ultrasonography screening in 96,278 uns elected employees. Thyroid 14 (11): 926-932.

37. Koufman JA, Amin MR, Panetti M (2000) Prevalence of reflux in 113 consecutive patients with laryngeal and voice disorders. Otolaryng Head Neck 123 (4):385-388. doi: 10.1067/mhn.2000.109935

Paper accepted for publication in European Archives of Oto-Rhino-Laryngology.

Remacle, A., Petitfils, C., Finck, C., \& Morsomme, D. (2016). DOI: 10.1007/s00405-016-4332-7 